\title{
Planning library buildings: Ten practical considerations
}

\author{
By Kate W. Ragsdale
}

\section{Follow these tips for a successful building project}

ibrarians rarely receive formal training in planning a new library building or a major library building renovation. Even the terminology used by architects and builders is unfamiliar to us. We do not have a crystal ball to guide us in visualizing the needs of our institutions 20 years into the future. We do not know how technology will change the way we provide access to information. So, how do we manage to be successful in handling the complex responsibility of planning library buildings? We devour the library literature; we consult with others who have had experience in planning library buildings; we learn from architects and university facility planners (who in turn learn from us); we share information informally through electronic mail--and we make some mistakes.

Here are ten practical tips, not necessarily in order of priority, to assist librarians who, in addition to their other responsibilities, find themselves planning a college or university library building. Of course, each building project is unique, but there are fundamental issues that apply to many, if not all, academic library construction projects.

1. Hire an interior designer. The services of a designer are important for both major library renovations and new library construction. We all know that designers coordinate colors, select finishes, and choose wall and floor coverings - all fundamental to the ambiance of the building. But architects, too, are often adept at making these selections. So why insist on a designer?
The additional services provided by a designer can make a significant difference in the quality of the finished product. Matching furniture design with the needs of the library, the designer lays out the arrangement of the furnishings within the space available. A designer's expertise in this phase of the project alone can save the librarian hours and hours of time and also help to prevent mistakes in the furniture selection process. The designer knows how much space to allow at the front of a file cabinet so that the drawers can be pulled out easily, or between study tables so that the chairs will not strike each other. A designer helps the librarian deal with issues of functionality in work room and office furnishings; is familiar with reliable manufacturers and products; is able to write specifications if bids must be let; is on site to troubleshoot when the furnishings are installed; and deals with the vendors to solve problems.

Many architectural firms employ their own interior designers, a situation that enhances effective communication among the librarian, the architect, and the designer throughout the project.

In the interest of economy, university and college administrators may suggest that an interior designer is an unnecessary luxury. If this should happen, the librarian might offer a compromise by suggesting that something else in the project could be deleted to free up funds to hire the services of a designer.

2. Remember the library signs. Early in the planning process make certain that the signs are to be a part of either the building contract or the interior design/furnishings contract. Amazingly enough, it is possible that the signage system will be overlooked by the architect. 
Unless they design libraries, hospitals, airports, or other public buildings, architects may be oblivious to the need for effective signage in library buildings. And sometimes architects balk at the multitude of signs needed to direct library users because they think the signs will interfere with the design of the building.

The librarian is the logical person to develop a list of signs (directional, room numbers, building directory, etc.) needed in the building. Although it is easier to draw up a list of signs once the building is partially completed, sometimes this list must be compiled even before construction begins. In this case, the librarian, using the drawings as a guide, must simply conceptualize. A visit to nearby libraries and hospitals can be useful in gathering information and ideas about appropriate signs for the library.

3. Include the book detection system in the building contract. The technical nature of book detection systems plus competitiveness in the book security system business in general combine to make it wise to include this system as a part of the building contract. The architect will gather information directly from vendors concerning the features of book detection systems, thereby relieving the librarian of the stress of serving as a liaison.

It is, of course, the responsibility of the librarian to alert the architect to desirable features in a book security system, to the need for compatibility with systems in other libraries on campus, and to preferences among the available book detection systems and installation options.

4. Pay careful attention to the accessibility of the building. In spite of requirements of the Americans with Disabilities Act (ADA), and civil rights laws for persons with disabilities passed prior to the ADA, important issues of accessibility may be overlooked, even in planning a new building. The ADA is specific in requiring that all new construction completed after January 1, 1993, must be accessible to users with disabilities.

Increasingly, architects understand the issues that librarians raise concerning accessibility. But architects may be looking only at requirements actually spelled out by the law rather than at fairly simple, maybe even inexpensive, adjustments which make it easier for patrons with disabilities to use the building.

One way to ensure careful attention to the accessibility of the building is to seek suggestions from library patrons with disabilities. Giv-

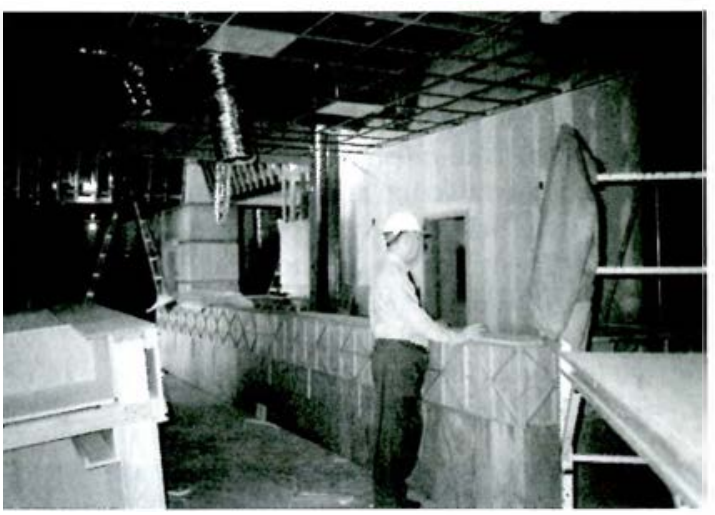

Take lots of photos to document progress throughout the project. 1) Feb. 1990-Reference Desk area, Eric and Sarah Rodgers Library for Science and Engineering, University of Alabama, Tuscaloosa.

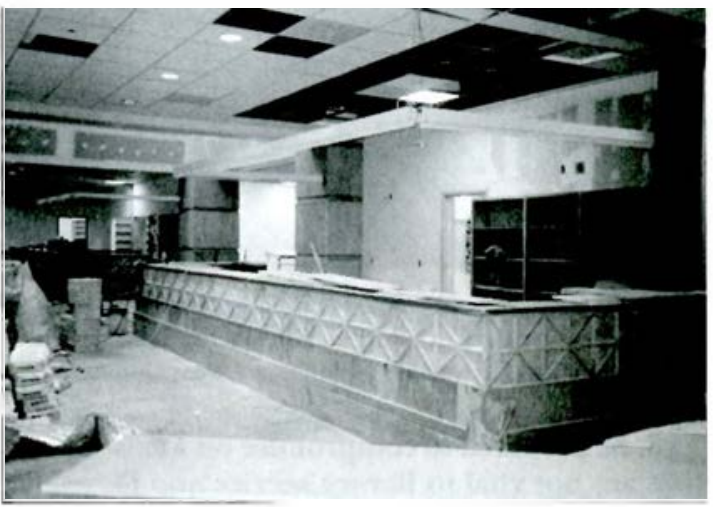

2) March 1990-Same area.

ing these library users the opportunity to review drawings and/or to visit the site as the building is being constructed, and to make suggestions as the project progresses, will go a long way toward making certain that the completed library building is truly accessible.

5. Take lots of photos throughout the project. Be sure that photos are taken on a regular basis-the "before" shots, the ground breaking, all stages of construction, vendors making installations, committees planning for the move, the move process itself, the building dedication ceremony. 
It is surprising how useful photos, even those taken by an amateur, tum out to be. Photos are a great way to keep the library staff and users informed of the progress of construction; for promotional displays and articles; for a scrapbook entry in the John Cotton Dana public relations competition; for the library archives; for displays during the building dedication; as mementos for library staff and donors.

At the end of the project, arrange to have a professional photographer (e.g., the university photographer) take artistic exterior and interior shots of the building, highlighting the best features of the building. These photos may be used in applying for an architectural award (such an AIA/ALA-LAMA Library Building Award) or submitted to journals that annually feature library architecture (such as American Libraries and Library Journal).

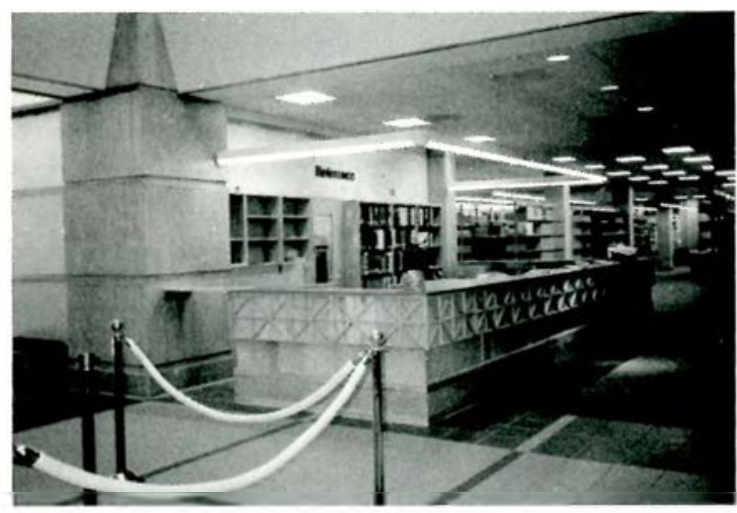

3) June 1990 - First week opened. Reference desk area, Eric and Sarah Rodgers Library for Science and Engineering, University of Alabama, Tuscaloosa.

6. Be prepared to compromise on items that are not vital to library service and to stand firm on the ones that are. Know the difference and make sure that the architect does, too. Giving up some shelving to cut costs is a compromise that might be feasible; additional shelving can be installed later as it is needed. And while decorative elements may be attractive, eliminating some of these items probably will not affect the level of library service. Examples of design features that librarians might actively promote are floor loads which are capable of handling future compact shelving and having only one public entrance/exit for the building.

Flexibility is an important attribute for library building planners; however, it is equally important for librarians to speak out on issues that will affect the level of service for library users.

7. Join the architect on weekly site inspections as soon as the finishes begin. It is important for the librarian to visit the site often during the entire project, but observation almost daily once the painting, carpeting installation, and trim finishes are being completed can be time well spent. Make arrangements to accompany the architect on weekly inspections as the project nears its end; also, help to develop the punch list.

Attention to detail throughout the final weeks can ensure a better product-and a much, much shorter punch list.

8. Be generous in estimating the amount of time you will spend on the project, and plan to accommodate your other responsibilities. Librarians who plan new and renovated buildings are also juggling other responsibilities; actually, this is true of almost everyone who is working on the project-the architect, the designer, the vendors, the subcontractors, the campus planners. The project superintendent on the site may be the only key person who is working full time on this one project.

With this in mind, the librarian will have to make arrangements to share responsibilities during this period or to delay other projects for a while. Extra student assistants or temporary staff members may be needed to fill in; adjusting schedules and responsibilities with supervisors and coworkers during the construction project may need to be considered.

Dealing with the many hours spent on planning new or renovated library buildings is one of the most difficult aspects of the project. This management issue should be handled directly from the beginning to help to maintain a positive attitude toward the new building and toward those who are planning it.

9. As much as possible, follow up informal communication in writing. The complexity of a building project contributes to lapses in communication, and circulating notes and memos can clear up misunderstandings before costly mistakes occur.

The files for a building project can be voluminous, in part because it is useful to make sure that communication (a casual conversa- 
tion in person, a telephone conversation, agreements at a meeting) is followed up in writing and that copies are forwarded to everyone concerned. Written communication of all approved change orders is especially important since these changes do not appear on the drawings.

At the beginning of each building project, an established line of communication should be explained to everyone involved. Librarians must conform to the recognized line of communication. At the outset, arrangements should be made for sending copies of written correspondence, and librarians must make sure that they are a part of this loop.

10. Keep complete files on each building project. Once the project is complete, library staff think that they will never forget even the most minute details of how to move a library, how to write bid specifications for ordering equipment, how to launch a public relations campaign for the new library, how to schedule library services during a move. But details fade as routines are once again assumed.

It is a good idea to ask each committee or individual responsible for an aspect of the project to develop a final report which includes methodology used, examples, mistakes made, and suggestions for better implementation during the next construction project. These files will assist the library in planning the next building venture, and they are also helpful when other libraries ask for assistance in planning a building.

Unless they design libraries, bospitals, airports, or other public buildings, arcbitects may be oblivious to the need for effective signage in library buildings.

The above tips are not in any particular order; each can contribute to the success of a construction project. We librarians muddle our way through the process of planning library construction. Each time we do it, we get better at it. Our success may be based in part on our eagerness to assist each other as well as to learn from one another.

\section{Entrust your endangered material to MAPS}

- Highest quality preservation microfilming - 150+ line resolution images

- MAPS patented exposing system-Exceptionally narrow density ranges for better duplication

- Polysulfide treatment-Protects your film against oxidation damage (measles)

- Herrmann \& Kraemer cameras-Highest quality, computer-controlled cameras

- Fast, reliable turnaround for your projects

- Facilitate scanning of film-High resolution, consistent density, blipping and frame numbering

Preserve your endangered material and prepare for our digital future. With an environmentally controlled laboratory and specially trained staff, MAPS is devoted exclusively to archival-quality preservation microfilming, storage of print masters, and film duplication services. Call MAPS for more information and prompt estimates.

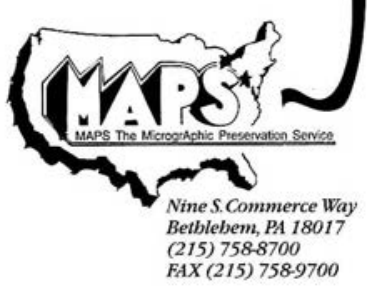

